\title{
Conhecimento sobre a utilização segura de agrotóxicos por agricultores da mesorregião do Norte Central do Paraná
}

\author{
Knowledge about the safe use of pesticides by farmers from Central \\ Northern Paraná State
}

\author{
Janaína Zorzetti ${ }^{1 *}$; Pedro Manuel Oliveira Janeiro Neves²; Patrícia Helena Santoro \\ Kelly Christiane Constanski ${ }^{1}$
}

\begin{abstract}
Resumo
Os agrotóxicos são considerados um importante fator de riscos para a saúde humana e têm sido objeto de vários estudos, tanto pela sua toxicidade como pela degradação ambiental. Este trabalho teve por objetivo diagnosticar o nível de conhecimento de agricultores da mesorregião do Norte Central do Paraná sobre a utilização segura de agrotóxicos. Para isso utilizou-se um questionário que abordou temas relacionados à intoxicações, uso de equipamento de proteção individual (EPI) e conhecimento sobre bulas e rótulos. Foram entrevistados 100 agricultores filiados às cooperativas da região. Após a análise das respostas, foi possível observar que a maioria dos agricultores fazia o uso incompleto do EPI em suas atividades diárias, ou não o utilizavam como foi constatado em todos os casos de intoxicação. Os termos utilizados nas bulas e rótulos de agrotóxicos não são adequadamente compreendidos pelos agricultores, contribuindo para aumento dos problemas no manuseio seguro desses produtos. O estudo permite concluir que é necessário um processo de capacitação e orientação por parte dos órgãos reguladores e das empresas envolvidas, tais como, empresas de insumos, cooperativas e órgãos de assistência técnica, para que a utilização mais criteriosa dos produtos possa diminuir os riscos à saúde das populações rurais e ao meio ambiente.

Palavras-chave: Intoxicação, exposição ocupacional, bulas e rótulos de agrotóxicos
\end{abstract}

\begin{abstract}
Pesticides are considered an important risk factor for human health and have been the subject of several studies, both for its toxicity and environmental degradation. This study aimed to diagnose the knowledge level of farmers from the Central Northern Paraná State on the safe pesticides use. For this we used a questionnaire that addressed issues related to intoxication, use of personal protective equipment (PPE) and knowledge about inserts and labels. We interviewed 100 farmers affiliated to cooperatives in the region. After analyzing the responses, we observed that most farmers did an incomplete use of PPE in their daily activities, or did not use it, as it was found in all cases of poisoning. The terms used in the pesticides inserts and labels are not properly understood by farmers, contributing to increased problems in the safe handling of these products. The study concludes that it is necessary to have a process of training and guidance from regulators and the companies involved, as inputs companies, cooperatives and technical assistance agencies aiming more judicious use of the products and decreasing the risks to health of rural populations and environment.
\end{abstract}

Key words: Poisoning, occupational exposure, inserts and pesticides labels

\footnotetext{
${ }^{1}$ Discentes do Curso de Doutorado em Agronomia, Universidade Estadual de Londrina, UEL, Londrina, PR. E-mail: jzorzetti@ hotmail.com; kconstanski@hotmail.com

${ }^{2}$ Prof. Dr., Programa de Pós-Graduação em Agronomia, Fitossanidade, Dept ${ }^{\mathrm{o}}$ de Agronomia, UEL, Londrina, PR. E-mail: pedroneves@uel.br

${ }^{3}$ Pesquisadora Dr ${ }^{\mathrm{a}}$, Instituto Agronômico do Paraná, IAPAR, Londrina, PR. E-mail: ph_santoro@yahoo.com.br

* Autor para correspondência
} 


\section{Introdução}

Os agrotóxicos começaram a ser difundidos no Brasil a partir da década de 1960, sendo considerados como solução científica para o controle das pragas que atingiam lavouras e rebanhos (PERES; MOREIRA; DUBOIS, 2003). Entretanto, o maior consumo se deu a partir de 1975, com o Plano Nacional de Desenvolvimento (PND), que condicionava a concessão de crédito rural à aquisição de agrotóxicos, ou seja, para obter os recursos do crédito rural, a cada financiamento requerido, era automaticamente incluída uma cota definida desses produtos (GARCIA, 1996). Em 2008, o Brasil ultrapassou os Estados Unidos e assumiu o posto de maior consumidor mundial de defensivos agrícolas, posição que ainda ocupa atualmente (ANVISA, 2010). Dentre os estados brasileiros, o Paraná é o terceiro maior consumidor, principalmente de produtos considerados "perigosos" e "muito perigosos", segundo a Classificação do Potencial de Periculosidade Ambiental (IBGE, 2012).

Os agrotóxicos auxiliam no controle de diversas pragas, o que pode proporcionar o aumento da produtividade (DOMINGUES et al., 2004). Entretanto, o uso inadequado e indiscriminado vem trazendo prejuízos ao homem e ao meio ambiente, além da seleção de populações de insetos resistentes e eliminação de inimigos naturais (SILVA; NOVATOSILVA; PINHEIRO, 2005; DOMINGUES, 2010).

Atualmente, os agrotóxicos são considerados como um sério problema de saúde pública tendo em vista relatos de casos graves de intoxicação por exposição direta ou indireta a esses agentes (FARIA et al., 2004; ARAUJO et al., 2007; FARIA; ROSA; FACCHINI, 2009). Os últimos dados lançados pelo Sistema Nacional de Informações TóxicoFarmacológicas (SINITOX, 2013) informaram que somente no ano de 2010, houve um registro de 5463 casos de intoxicação e/ou envenenamento por produtos de uso agrícola. Provavelmente este número deve ser muito maior se forem considerados os casos não notificados, pois, de acordo com estimativas do Ministério da Saúde, para cada caso notificado de intoxicação, há cerca de 50 não notificados (CASADO, 2005).

Apesar da existência de regulamentações quanto à comercialização e manejo dos agrotóxicos, muitos usuários não respeitam todas as regras impostas pela legislação, e não tomam os devidos cuidados durante o manuseio desses (FERNANDES et al., 2012). Um meio de se evitar riscos de contaminação e intoxicação seria a leitura e entendimento das bulas e rótulos dos produtos, que trazem informações necessárias para que possam ser utilizados adequadamente (ANDEF, 2001). Contudo, a maioria dessas informações não é seguida devido à falta de compreensão pelos trabalhadores (PERES; MOREIRA; LUZ, 2007).

Muitos casos de intoxicação poderiam também ser evitados com a utilização de proteção adequada, como o Equipamento de Proteção Individual (EPI) que é destinado a proteger a integridade física do trabalhador (AGOSTINETTO et al., 1998). Entretanto, não é utilizado por todos os agricultores, e quando utilizado, geralmente é feito de maneira incorreta (ÁVILA et al., 2009).

O objetivo desse trabalho foi avaliar o conhecimento dos agricultores da mesorregião do Norte Central do Paraná sobre informações básicas para a utilização segura de agrotóxicos; investigar os casos de intoxicação e as suas principais causas; levantar possíveis sugestões para reduzir a utilização inadequada desses produtos.

\section{Material e Métodos}

A pesquisa foi realizada entre os meses de janeiro a dezembro de 2007 em municípios situados na mesorregião do Norte Central Paranaense (Rolândia, Arapongas, Cambé, Pitangueiras, Alvorada do Sul, Bom Sucesso, Sertanópolis, Jaguapitã, Florestópolis, Tamarana, Mauá da Serra e Faxinal). Essa região concentra, no Paraná, o maior número de pessoas ocupadas em atividades agrícolas. 
$\mathrm{Na}$ última década houve grande modernização agropecuária e desenvolvimento do processo de agroindustrialização. Sua base agropecuária é de grande competitividade, apresentando importante expansão dos níveis de produtividade e relacionamentos com o mercado internacional, com méritos às culturas de soja, milho e cana-de-açúcar e a criação de bovinos e aves, responsáveis pelo crescimento do setor na região (IPARDES, 2004).

Foi utilizado como instrumento de coleta de dados, um questionário aplicado a 100 agricultores escolhidos ao acaso, abordados nas propriedades, encontros de produtores e nas sedes das cooperativas. Como pré-requisito para ser entrevistado, o agricultor deveria habitualmente realizar a leitura dos rótulos e bulas de agrotóxicos antes de sua utilização, sendo ele encarregado ou não da aplicação. A amostra foi probabilística dentro do conjunto de agricultores associados às cooperativas, considerando como fator de exclusão os cooperados que não liam os rótulos e bulas de agrotóxicos.

Inicialmente, uma carta de apresentação foi fornecida ao entrevistado para o esclarecimento do objetivo do trabalho. As questões aplicadas foram divididas em dois segmentos. No primeiro, foram abordados os aspectos sócios econômicos, como o perfil do produtor e da propriedade. No segundo, investigaram-se as práticas e os cuidados na utilização de agrotóxicos, e os conhecimentos e percepção dos riscos inerentes à utilização dos mesmos. Essa pesquisa foi realizada com produtores filiados as cooperativas da região a fim de abordar um universo onde supostamente os agricultores seriam orientados por responsáveis técnicos sobre manejo correto de agrotóxicos e contassem com melhores condições de trabalho mediante ao auxílio das cooperativas.

O questionário foi composto por 37 questões, estruturadas (múltipla escolha) e não estruturadas (discursivas), incluindo questões práticas onde diferentes rótulos de agrotóxicos foram apresentados aos entrevistados a fim de testar seu conhecimento sobre as cores contidas nos rótulos, as quais definem a classe toxicológica, e também os pictogramas, que indicam os cuidados que devem ser considerados na utilização desses produtos. Eles foram questionados também sobre a ocorrência de casos de intoxicações e providências tomadas, utilização correta de EPI, compreensão dos termos contidos nas bulas e rótulos dos produtos, conhecimento sobre métodos de controle alternativo de pragas, grupos de agrotóxicos mais utilizados, transporte e armazenamento dos produtos e destino final de embalagens vazias.

Os dados foram coletados por um único entrevistador, anotados fielmente, tabulados e transformados em médias e porcentagens para melhor interpretação dos mesmos. Para a realização da análise estatística descritiva, foram utilizados os recursos do programa Microsoft Excel 2007 (Windows-Microsoft $®$ ).

\section{Resultados e Discussão}

1. Perfil sócio econômico: A faixa etária dos entrevistados variou entre 16 a 73 anos, com a maioria (37\%) entre 46 a 55 anos. A maior parte dos agricultores (44\%) possuíam propriedades acima de 100 ha, caracterizadas principalmente pelo cultivo de soja, milho, trigo e cana-de-açúcar. Esse tipo de cultura prevaleceu em toda a região estudada, até mesmo nas pequenas propriedades ( $5 \mathrm{ha}$ ), entretanto essas diferiam quanto a disponibilidade de recursos financeiros e tecnológicos (Figura 1).

Cerca de $50 \%$ dos agricultores contratavam funcionários fixos para a realização das tarefas agrícolas e $48 \%$ contavam apenas com mão de obra familiar, que era composta predominantemente por quatro pessoas. Todos os agricultores eram filiados a cooperativas, variando o tempo de cooperação entre 5 a 43 anos. Em relação ao grau de escolaridade, observou-se que $37 \%$ possuíam o $1^{\circ}$ grau completo ou incompleto, $35 \%$ o segundo grau e $28 \%$ curso superior completo ou incompleto. 
Os dados obtidos estão, em partes inseridos no perfil da região, onde é evidenciada a importância da agricultura familiar pelo predomínio de pequenas (até 48 ha) e médias (48 a 180 ha) explorações agrícolas, com mão de obra composta em sua maioria pelos próprios membros da família, enquanto os assalariados representam cerca de 30\%. Em geral os agricultores são os proprietários da terra, utilizam praticamente toda a área que possuem e tem na exploração das lavouras a sua atividade principal, a qual está concentrada basicamente no cultivo de cinco produtos principais (soja, milho, cana-deaçúcar, rebanho bovino e aves) (IPARDES, 2004).

2. Utilização de agrotóxicos: Os produtos mais utilizados pelos entrevistados foram os herbicidas com 40\%, seguidos pelos inseticidas com 36\% e fungicidas com 24\%. Essa proporção se deve ao grande número de áreas cultivadas com cana-deaçúcar, que é uma cultura mais exigente em tratos culturais com herbicidas.

Os locais de maior aquisição de agrotóxicos citados foram as cooperativas e as revendas de insumos com 90 e 18\% respectivamente. Aproximadamente $98 \%$ dos produtores consultaram um engenheiro agrônomo na hora da compra, e os outros $2 \%$ eram os agricultores com graduação em agronomia. Esse elevado número de agricultores que receberam assistência técnica no momento da compra de agrotóxicos se deve a sua vinculação com as cooperativas, que disponibilizam técnicos para avaliar as áreas e recomendar os produtos. Muitas vezes essa assistência não é realizada em algumas propriedades, especialmente para pequenos agricultores, como observado por Monqueiro, Inácio e Silva (2009), onde 28\% dos produtores de hortaliças e frutas da região de Araras/SP não contavam com orientação de engenheiros agrônomos. Lima et al. (2009), também verificaram que $43 \%$ dos agricultores de pêssego no Estado do Rio Grande do Sul não receberam nenhum tipo de assistência técnica durante a safra 2007/2008, e desenvolveram as atividades baseados no senso comum.
No momento da escolha do agrotóxico, 71\% dos agricultores priorizaram a eficiência do produto utilizado na safra anterior. $\mathrm{O}$ preço do produto influenciou na escolha de $61 \%$ e a recomendação da cooperativa foi decisiva para $58 \%$ dos entrevistados. Apenas 17\% levaram em consideração a toxicidade e ainda $4 \%$ fizeram suas escolhas baseadas em conversas com vizinhos e trocas de informações sobre o rendimento e eficiência do produto.

O conhecimento sobre métodos de controle alternativo de pragas foi citado por $66 \%$ dos entrevistados. Desses, $87 \%$ afirmaram já ter utilizado o vírus Baculovirus anticarsia (AGMNPV) no controle da lagarta da soja Anticarsia gemmatalis, e interromperam o uso, devido à falta de eficiência observada. E 15\% dos agricultores citaram a liberação de inimigos naturais como Cotesia flavipes (Cameron, 1981) (Hymenoptera: Braconidae).

\section{Cuidados realizados na manipulação} de agrotóxicos: Do total de entrevistados, 60\% realizavam as aplicações de agrotóxicos na propriedade e 40\% repassavam a atividade a funcionários. Todos os entrevistados afirmaram saber o que é o EPI e $77 \%$ responderam que faziam o uso, porém $23 \%$ dos que realizavam a aplicação não o utilizavam.

Dentre os entrevistados que afirmaram adotar o uso de EPI como método de proteção, 54\% o faziam de maneira incompleta, e apenas quando consideravam o produto muito tóxico, procuravam utilizar todo o equipamento. Dos que responderam não utilizam EPI, 20\% alegaram que a aplicação dos agrotóxicos era realizada em tratores com cabine fechada, e se consideravam protegidos de qualquer intoxicação.

Os agricultores que utilizam o EPI de forma incompleta geralmente optavam por proteger as partes mais expostas aos agrotóxicos, e por onde consideravam serem os maiores meios de contaminação. Os itens mais utilizados e citados pelos entrevistados foram a máscara e as luvas (Tabela 1). O mesmo foi constatado por Ávila et 
al. (2009), em entrevistas com trabalhadores rurais em Minas Gerias os quais acreditavam que apenas o uso de máscara ou luvas poderia prevenir possível intoxicação e que esta só era ocasionada por ingestão ou respiração e não por via dérmica.

Tabela 1. Equipamentos de proteção individual utilizados pelos agricultores.

\begin{tabular}{lc}
\hline $\begin{array}{c}\text { Componentes do Equipamento } \\
\text { de Proteção Individual }\end{array}$ & Entrevistados (\%) \\
\hline Máscara & 62 \\
Luvas & 56 \\
Roupa & 37 \\
Bota & 30 \\
Avental & 17 \\
Boné árabe & 15 \\
Chapéu & 11 \\
Óculos & 9 \\
\hline
\end{tabular}

Fonte: Elaboração dos autores.

Os principais motivos apresentados pelos entrevistados para o não uso ou uso incompleto do EPI foram o desconforto e o calor com 61 e $43 \%$ respectivamente. Além desses motivos, 12\% não consideravam importante a utilização de EPI. Essa crítica sobre o incômodo em trabalhar com o EPI também foi relatada em diversas entrevistas com agricultores que realizaram a aplicação de produtos químicos, sendo um problema tecnológico conhecido e que deveria ganhar mais atenção ou até mesmo uma versão mais confortável que estimulasse o uso completo desse equipamento (LIMA et al., 2009; ÁVILA et al., 2009; MONQUEIRO; INÁCIO; SILVA, 2009; MARQUES; NEVES; VENTURA, 2010).

Dentre o grupo de entrevistados que não realizavam a aplicação de agrotóxicos, 90\% afirmaram que repassavam as informações lidas para os responsáveis pela aplicação, e 10\% alegaram que seus funcionários eram submetidos a cursos informativos ou já eram bens instruídos quanto à aplicação dos defensivos. As informações que consideravam mais importantes na orientação dos funcionários eram os cuidados na aplicação e a dosagem dos produtos (Tabela 2).

Ao repassar as atividades de aplicação de agrotóxicos para outros, 90\% dos entrevistados afirmaram disponibilizar o EPI para os funcionários.

Os demais alegaram que não o faziam, pois os funcionários não achavam necessário e não o utilizavam. Entre os agricultores que disponibilizavam o equipamento, $57 \%$ exigiam o seu uso e $43 \%$ não, deixando claro que passavam orientações quanto à importância, mas que a responsabilidade da utilização cabia ao aplicador.

Tabela 2. Informações contidas em bulas e rótulos de agrotóxicos lidos pelos agricultores e que são repassadas aos responsáveis pela aplicação.

\begin{tabular}{lc}
\hline \multicolumn{1}{c}{ Informações mais citadas } & Entrevistados (\%) \\
\hline Informações sobre cuidados na & 47 \\
aplicação & 25 \\
Dose recomendada & 17 \\
Uso de EPI & 17 \\
Regulagem correta dos & 11 \\
pulverizadores & 11 \\
Preparo da calda & 11 \\
Aplicação correta & 8 \\
Perigos & 8 \\
Grau de periculosidade & 5 \\
Modo de manusear o produto & 5 \\
Toxicidade & 5 \\
Horário de aplicação & 3 \\
Destino das embalagens & \\
Evitar desperdício &
\end{tabular}

Fonte: Elaboração dos autores.

O armazenamento de agrotóxicos em local exclusivo e fechado, sem riscos de contaminação é estabelecido pela Lei 7802 (BRASIL, 1989), entretanto apenas $28 \%$ dos entrevistados o realizavam de maneira correta. Cerca de $30 \%$ faziam o armazenamento em barracões não apropriados, 
juntamente com outros implementos e insumos. Outros 16\% armazenavam em barracões abertos e sem segurança adequada, 6\% em garagens, e $18 \%$ retiravam os produtos nas cooperativas e revendas no momento da aplicação, alegando maior comodidade e segurança. A armazenagem incorreta também foi verificada em outros estudos, onde cerca de $50 \%$ dos agricultores entrevistados armazenavam os produtos incorretamente, até mesmo dentro de suas casas, o que expande o risco de exposição e contaminação a um maior número de pessoas (MONQUEIRO; INÁCIO; SILVA, 2009; FERNANDES et al., 2012).

O transporte dos agrotóxicos até a propriedade ou local de aplicação, era realizado de maneira incorreta por $20 \%$ dos entrevistados, que afirmaram transportar os produtos em seus carros fechados, juntamente com pessoas ou outros materiais, correndo assim grandes riscos de contaminação. O transporte de maneira correta, em utilitários com carroceria aberta ou fechada, como disposto no Decreto-Lei $n^{\circ} 4074$, de 4 de janeiro de 2002, que regulamentou a lei n. ${ }^{\circ} 7.802$, de 11 de julho de 1989, (BRASIL, 2002), era realizado por $80 \%$ dos produtores.

Isso demonstra a conscientização dos agricultores sobre os perigos do transporte incorreto e representa também o maior desenvolvimento da região objeto dessa pesquisa, onde a maioria dos entrevistados possuíam meios de transporte adequados à atividade rural. Além disso, muitos agricultores relataram que realizavam o transporte correto em função da fiscalização que polícia rodoviária federal realizava frequentemente na região, aplicando as punições necessárias a quem infringir a lei. Esse fato demonstra a eficiência da fiscalização e aplicação de punições no cumprimento das leis. Muitas exigências e cuidados com a utilização dos agrotóxicos poderiam ser realizados com maior rigor se houvesse uma fiscalização eficiente, que também faria o papel de instrução e conscientização para muitos produtores rurais.

O descarte correto de embalagens vazias era realizado por $100 \%$ dos entrevistados, que afirmaram armazenar na propriedade até somar uma quantidade apropriada para a devolução. O grande incentivo para a destinação correta das embalagens vazias era a forma de devolução facilitada pelas cooperativas e pela ANPARA (Associação Norte Paranaense de Revendedores de Agroquímicos), por meio de locais próprios para recebimento das embalagens em cidades próximas às propriedades.

Em muitas regiões do Brasil, como Araras/SP e Rio de Janeiro, onde não existe esse tipo de incentivo para a devolução das embalagens, os agricultores não realizavam o descarte correto, alegando excesso de burocracia e a falta de locais apropriados próximos às propriedades, o que acarreta gastos com o transporte (CASTRO; CONFALONIERI, 2005; MONQUEIRO; INÁCIO; SILVA, 2009).

\section{Conhecimento sobre rótulos e bulas de} agrotóxicos: Segundo o Decreto-Lei ${ }^{\circ} 4074$, de 4 de janeiro de 2002 (BRASIL, 2002), rótulos e bulas de agrotóxicos devem conter, entre outras informações, a procedência do produto, grau de toxicidade, forma de utilização, recomendações para que a bula seja lida antes da aplicação do agrotóxico, frases de advertência e símbolos de perigo padronizados de acordo com sua classe toxicológica além de instruções para o caso de acidentes. Dentre essas, as que foram consideradas mais importantes pelos entrevistados foram a dosagem (64\%) e a praga para qual o produto foi recomendado (34\%). Apenas 20\% afirmaram ler informações sobre a toxicidade do produto, e os perigos que ele oferece, bem como os cuidados que devem ser tomados ao utilizá-lo (Tabela 3). 
Tabela 3. Informações contidas nos rótulos de agrotóxicos consideradas de maior importância pelos agricultores.

\begin{tabular}{lc}
\hline \multicolumn{1}{c}{$\begin{array}{c}\text { Informações contidas nos } \\
\text { rótulos de agrotóxicos }\end{array}$} & Entrevistados (\%) \\
\hline Dosagem & 64 \\
Indicação de uso & 34 \\
Toxicidade & 20 \\
Cuidados e Precauções & 20 \\
Modo de usar & 16 \\
Modo de aplicar & 14 \\
Carência & 14 \\
Composição & 8 \\
Validade & 6 \\
Primeiros socorros & 5 \\
Cuidados com o ambiente & 4 \\
Sintomas de Alarme & 3 \\
\hline
\end{tabular}

Fonte: Elaboração dos autores.

Apesar da disponibilidade de informações contidas em todas as bulas e rótulos de agrotóxicos, nem todas são lidas e compreendidas pelos agricultores. Dentre os entrevistados, $55 \%$ afirmaram entender o conteúdo das bulas e rótulos de agrotóxicos sem dificuldades, e 45\% confessaram não haver uma boa compreensão. A maior dificuldade citada foi o tamanho da letra (95\%) seguida pela compreensão dos termos técnicos utilizados nas explicações (42\%). O tamanho e a falta de objetividade do texto também foram empecilhos citados por 35\% dos entrevistados, que alegaram não ter paciência para ler completamente e encontrar as informações necessárias.

Para que estas informações sejam compreendidas, elas devem ser legíveis, pois a dificuldade em ler o texto e distinguir as palavras atrapalha a organização das ideias e dificulta sua compreensão (IIDA, 2005). A falta de entendimento sobre os riscos aos quais os agricultores se expõem ao aplicar tais produtos demonstra que as advertências nos rótulos e bulas de agrotóxicos não têm eficácia e não cumprem totalmente o papel ao qual se destinam (YAMASHITA; SANTOS, 2009).
A maioria dos entrevistados afirmou compreender facilmente as informações contidas nos rótulos, entretanto, diante da apresentação de alguns termos como intervalo de reentrada, período de carência, classe toxicológica, antídoto e sintomas de alarme apenas $21 \%$ acertaram o significado de todos eles. A maior dificuldade com o vocabulário foi com o significado de 'intervalo de reentrada', onde apenas $31 \%$ deles responderam corretamente. Os demais entrevistados acreditavam que esse seria o intervalo de tempo até a próxima aplicação do agrotóxico na lavoura. A classe toxicológica foi o termo mais conhecido pelos agricultores, onde $87 \%$ responderam de maneira correta (Figura 2).

A compreensão sobre a toxicidade dos produtos indicada pelas diferentes cores dos rótulos, e a periculosidade que elas demonstram foi analisada ao apresentar aos agricultores os rótulos dos agrotóxicos com diferentes faixas (classe I - vermelha, classe II - amarela, classe III - azul e classe IV - verde). Dos entrevistados, 86\% afirmaram serem capazes de diferenciar a toxicidade dos produtos pelas diferentes cores dos rótulos, entretanto, apenas $24 \%$ desses acertaram as quatro classes toxicológicas.

A utilização de pictogramas nos rótulos dos agrotóxicos tem a intenção de superar as barreiras impostas pela linguagem escrita, podendo ser compreendidos por pessoas não alfabetizadas e por estrangeiros (IIDA, 2005). Dentre os entrevistados, $70 \%$ afirmaram conhecer e observar os pictogramas na hora da leitura e manuseio dos agrotóxicos. Para esses, foi apresentado uma lista com seis pictogramas diferentes e $83 \%$ deles responderam corretamente toda a sequência.

Para 30\% dos entrevistados que afirmou não observar, ou não conhecer os pictogramas estampados nos rótulos, a maior dificuldade relatada estava na compreensão dos desenhos. Além disso, não davam muita importância a eles por considerarem que as figuras não chamavam muito a atenção sobre os perigos relacionados aos produtos, exceto quando era imagem representada 
pela caveira. Isso expõe a falta de funcionalidade dos pictogramas para muitos agricultores, pois, de acordo com Sanders e McCormick (1993), o uso dessas imagens deve retratar fielmente de forma visual o que se pretende dizer com o texto.

Os estudos que avaliam o grau de entendimento dos agricultores em relação às bulas e rótulos dos agrotóxicos são de grande importância na elaboração de estratégias para uma manipulação segura desses produtos e para a viabilização de programas visando à redução de intoxicações (CASTELO BRANCO, 2003). Dessa forma, é fundamental compreender a necessidade dos agricultores em relação às alterações que devem ser realizadas nas bulas e rótulos de agrotóxicos. Dentre os entrevistados, 95\% sugeriram que algumas modificações deveriam ocorrer na escrita das bulas e rótulos a fim de facilitar sua compreensão. As mais citadas foram o aumento no tamanho das letras, especialmente quando descrevem os riscos que o produto oferece; uso de uma linguagem mais simples para facilitar o entendimento e busca de informações, com instruções mais objetivas, que possam ser compreendidas por agricultores e não apenas por técnicos e pessoas com elevado grau de escolaridade. Alguns agricultores consideraram a importância de incluir nos rótulos dos agrotóxicos algum tipo de aviso que fosse capaz de transmitir medo aos agricultores, para que estes ficassem cientes sobre a real existência dos perigos de intoxicação.

\section{Avaliação dos casos de intoxicação por} agrotóxicos: Casos de intoxicação foram registrados por $13 \%$ dos entrevistados, sendo que $92 \%$ desses recorreram ao auxílio médico e $8 \%$ recorreram à automedicação, ingerindo leite, refrigerante, e outros recursos que julgavam combater os efeitos tóxicos dos venenos, mesmo não estando citados entre os antídotos contidos nos rótulos. Do total de entrevistados que buscou auxílio médico, 15\% permaneceram internados.

A automedicação é extremamente perigosa, e muito comum no meio rural. Muitos casos de intoxicação, que poderiam ser atendidos e tratados com antídotos específicos, tornam-se casos graves, e muitas vezes levam a óbito. Em um estudo realizado por Martins et al. (2012), apenas 28\% dos trabalhadores rurais entrevistados que consideraram ter sofrido intoxicação, procuraram ajuda médica pelo menos uma vez na vida para tratar os sintomas. O restante afirmou ter o costume da automedicação e/ou recorrer a algum amigo ou balconista de farmácia.

O conceito de intoxicação não está bem claro para os trabalhadores, que consideram casos de intoxicação somente aqueles que precisarem realmente de socorro médico. Mal-estares durante ou após aplicações não são considerados sinais de intoxicação na opinião dos entrevistados. Com isso, $35 \%$ afirmaram já ter sentido algum tipo de mal-estar, como dores de cabeça (37\%), tontura e vômito $(23 \%)$, fraqueza (6\%), sangramento, ânsia de vômito, dores de estômago e até mudança na cor da urina, $(3 \%)$.

Essa falta de entendimento sobre toxicidade também foi analisada por Monqueiro, Inácio e Silva (2009), onde o conceito que as pessoas geralmente possuem sobre o assunto é de que a toxicidade oral aguda é o caso mais perigoso. Entretanto, esse não é o maior risco de intoxicação, pois raramente alguém irá ingerir o produto. $\mathrm{Na}$ realidade, os casos mais preocupantes de intoxicação estão relacionados ao contato do produto ou da calda com a pele. Assim, os trabalhadores que aplicam rotineiramente agrotóxicos devem se submeter periodicamente a exames médicos, a fim de analisar os efeitos crônicos da intoxicação.

As intoxicações podem ocorrer de três formas. A primeira é pela exposição a um determinado produto químico em grandes dosagens por um curto período, o que leva aos efeitos agudos. A associação causa/efeito é, geralmente, fácil de ser estabelecida, podendo ser caracterizado por náusea, vômito, cefaleia, tontura, desorientação, hiperexcitabilidade, irritação de pele e mucosas, fasciculação muscular, dificuldade respiratória, hemorragia, convulsões, coma e morte. A segunda forma pode ser leve ou 
moderada, dependendo da quantidade de veneno absorvido, o que leva a efeitos subagudos. A terceira forma de intoxicação é mais preocupante, devido ao seu difícil reconhecimento clínico. Ela está relacionada com exposições aos agrotóxicos por longos períodos e em baixas concentrações, e leva a efeitos crônicos. A intoxicação crônica caracteriza-se por surgimento tardio, em meses ou anos e pelo acarretamento de danos irreversíveis, do tipo paralisias e neoplasias (PERES; MOREIRA; DUBOIS, 2003).

Os agrotóxicos podem penetrar no corpo humano através da ingestão, respiração, olhos ou absorção pela pele (THUNDIYIL et al., 2008; VITALI et al., 2009; FARAHAT et al., 2010; NGO; O’MALLEY; MAIBACH, 2010). Quando foi questionado aos agricultores sobre as vias de absorção de agrotóxico pelo ser humano, somente $14 \%$ dos entrevistados citaram todas elas. As mais citadas foram a dérmica $(78 \%)$, oral e respiratória (60\%) e ocular (21\%), e 6\% deles desconheciam as principais formas de absorção.

A exposição aos agrotóxicos pode se dar de diversas maneiras durante o contato dos agricultores com os produtos, e assim aumentar as chances de intoxicação. As atividades onde houve os maiores casos de intoxicações foram no momento da aplicação dos produtos ou durante o preparo da calda e no tratamento de sementes. O manuseio de agrotóxicos e a deriva vinda de aplicações por vizinhos também foram citadas (Tabela 4).

Tabela 4. Atividades citadas pelos agricultores onde ocorreram os casos de intoxicações.

\begin{tabular}{lc}
\hline $\begin{array}{c}\text { Atividades em que ocorreram } \\
\text { as intoxicações }\end{array}$ & $\begin{array}{c}\text { Casos de Intoxicação } \\
(\%)\end{array}$ \\
\hline Aplicação de produtos & 54 \\
Preparo da calda & 31 \\
Tratamento de sementes & 31 \\
Manuseio dos produtos & 23 \\
Deriva & 8 \\
\hline
\end{tabular}

Fonte: Elaboração dos autores.
Os trabalhadores rurais participam praticamente de todas as atividades envolvendo os agrotóxicos, desde a mistura/preparação da calda, aplicação e lavagem do maquinário, o que aumenta o risco de intoxicação devido ao maior contato (MARTINS et al., 2012; SILVA; NOVATO-SILVA; PINHEIRO, 2005). Além disso, segundo Agostinetto et al. (1998), a aplicação de agrotóxicos na presença de ventos provoca deriva, que é uma das principais causas de intoxicação do aplicador e demais pessoas no meio rural, podendo também causar contaminação de ambientes adjacentes.

A absorção dérmica pode variar conforme a formulação empregada, temperatura, umidade relativa do ar, regiões do corpo, tempo de contato com o produto, existência de feridas e outros (MOREIRA et al., 2002). Considerando que a maior parte dos agrotóxicos é absorvida através da pele a proteção corporal pelo uso completo do EPI é fundamental para reduzir a absorção e o risco de intoxicações (CATANO et al., 2008; VITALI et al., 2009).

Em todos os casos de intoxicações relatados pelos entrevistados, foi constatado que os aplicadores não utilizam EPI, ou o utilizavam de forma incompleta, o que comprova a importância do equipamento para a proteção do agricultor. A ausência do EPI ou utilização ineficiente representa grande perigo à saúde do aplicador, causando elevação significativa no número de intoxicações (MONQUEIRO; INÁCIO; SILVA, 2009).

Os inseticidas foram responsáveis por $62 \%$ das intoxicações, $31 \%$ herbicidas e $8 \%$ fungicidas; o que está de acordo com diversos trabalhos, que se referem aos inseticidas como responsáveis pelo maior número de intoxicações (MARQUES; NEVES; VENTURA, 2010; JACOBSON et al., 2009; CERQUEIRA et al., 2010; FARIA, ROSA, FACCHINI, 2009). As intoxicações por inseticidas estão provavelmente associadas ao modo de ação destes produtos, a maioria neurotóxicos, que em seres humanos tem ação semelhante. 
A falta de instruções e a necessidade de maiores esclarecimentos em relação ao uso de EPI, além dos perigos que os agrotóxicos oferecem foram relatadas por $60 \%$ dos entrevistados como as principais causas da ocorrência de intoxicações. Eles afirmaram que os fabricantes de agrotóxicos, as cooperativas, revendas, e os agrônomos responsáveis pela assistência técnica, deveriam dar mais atenção a isso, não apenas recomendando o produto, mas também explicando outras informações como os perigos, riscos de intoxicação, modo de atuação dos agrotóxicos no organismo humano e os efeitos das intoxicações em longo prazo.

Essa necessidade de informação foi observada durante a entrevista, onde alguns agricultores acreditavam que os agrotóxicos lançados recentemente são formulados com novas tecnologias, o que os torna menos perigosos ou "mais fracos" em relação aos produtos que existiam antigamente. A falta de esclarecimento sobre a manipulação de agrotóxicos contribui para casos de intoxicações que poderiam ser evitados se houvessem maiores informações e uma conscientização de que os agrotóxicos, quando não utilizados de modo correto, podem gerar um grande dano à saúde de quem entrar em contato com eles (MONQUERIO; INÁCIO; SILVA, 2009).

Os dados obtidos no presente estudo indicam que, apesar da necessidade de uma maior conscientização a respeito da utilização segura desses produtos, a maioria dos agricultores se preocupava em realizar os procedimentos corretos a fim de evitar casos de intoxicações, e demonstraram algum conhecimento sobre o assunto abordado. Entretanto, devemos considerar que a região onde a pesquisa foi efetuada, Norte Central do Estado do Paraná, pode ser considerada como uma das mais produtivas e de melhor nível sócio econômico no meio rural (IPARDES, 2013). Os casos mais preocupantes encontram-se nas regiões rurais remotas e carentes onde o nível de instrução é menor, o que aumenta a limitação de cuidados e probabilidade da utilização incorreta dos agrotóxicos.
Deste modo é premente que haja uma fiscalização dos órgãos reguladores governamentais e que esses tomem medidas que obriguem os fabricantes, revendedores e técnicos a esclarecer os perigos para a saúde humana da utilização destes produtos. É também primordial que sejam feitas campanhas para o uso correto e consciente destes produtos, utilizando-os apenas quando necessário. Estas campanhas deveriam ser realizadas através de cursos, palestras, folhetos explicativos e até mesmo conversas informais entre os técnicos e os agricultores, ou seja, utilizando uma forma mais dinâmica de chamar a atenção do agricultor.

\section{Considerações finais}

A utilização de agrotóxicos ocorre de forma inadequada por parte dos agricultores entrevistados. Falta maior conscientização para um manuseio seguro e instruções sobre os perigos que os agrotóxicos oferecem, pois não souberam responder, ou responderam de forma incorreta às perguntas de fundamental importância à sua própria segurança.

A maioria dos produtores leem os rótulos, mas a compreensão é comprometida por aspectos relacionados ao tamanho de letra e falta de objetividade do texto. Dessa forma, sugeriram modificações para um melhor entendimento, como rótulos e bulas com letras maiores, texto com maior clareza, linguagem voltada ao produtor rural e formas mais chocantes de alertar sobre os perigos causados pelo uso incorreto dos agrotóxicos. Os entrevistados acrescentaram ainda que deveria haver maior empenho de técnicos das cooperativas e das empresas responsáveis pelos agrotóxicos em esclarecer sobre os perigos causados pelos agrotóxicos e a maneira correta de utilizá-los a fim de evitar acidentes.

O EPI não é utilizado de forma completa por todos os agricultores, que o consideram desconfortável ou desnecessário. As partes mais utilizadas são as luvas e máscara, consideradas de maior importância pelos entrevistados. 
Em todos os casos de intoxicações e mal-estares relatados pelos entrevistados, foi constatado que não faziam o uso adequado de EPI e não compreendiam informações contidas nos rótulos.

A pesquisa foi realizada em um universo limitado a produtores que recebem orientações dos engenheiros agrônomos das cooperativas e muitas vezes não as seguem ou não as compreendem. Assim, para se obter uma visão mais ampla dos fatos abordados seria necessário a realização de novas pesquisas focando agricultores não filiados a cooperativas, com assistência técnica proveniente de outra fonte ou sem nenhum tipo de assistência, pertencentes a regiões menos tecnificadas ou pequenas propriedades com cultivos diferenciados.

\section{Referências}

AGOSTINETTO, D.; PUCHALSKI, L. E. A.; AZEVEDO, R.; STORCH, G.; BEZERRA, A. J. A.; GRÜTZMACHER, A. D. Utilização de equipamentos de proteção individual e intoxicações por agrotóxicos entre fumicultores do município de Pelotas-RS. Pesticidas: Revista de Ecotoxicologia e Meio Ambiente, Curitiba, v. 8, p. 45-56, 1998.

ARAUJO, A. J.; LIMA, J. S.; MOREIRA, J. C.; JACOB, S. C.; SOARES, M. O.; MONTEIRO, M. C. M.; AMARAL, A. M.; KUBOTA, A.; MEYER, A.; COSENZA, C. A. N.; NEVES, C.; MARKOWITZ, S. Exposição múltipla a agrotóxicos e efeitos à saúde: estudo transversal em amostra de 102 trabalhadores rurais, Nova Friburgo, RJ. Ciência \& Saúde Coletiva, Rio de Janeiro, v. 12, n. 1, p. 115-130, 2007.

ÁVILA, R. A.; REZENDE, D. M. L. C.; RESENDE, I. L. C.; REZENDE, G. A. A. Trabalho rural e agrotóxicos: Estudo de caso na microbacia do córrego água limpa, município de Campos Altos, Minas Gerais. Pesticidas: Revista de Ecotoxicologia e Meio Ambiente, Curitiba, v. 19, p. 73-80, 2009.

ASSOCIAÇÃO NACIONAL DE DEFESA VEGETAL - ANDEF. Manual de uso correto de equipamentos de proteção individual. Campinas: Linea Creativa, 2001. Disponível em: <http://www.andefedu.com.br/uploads/ $\mathrm{img} / \mathrm{manuais} /$ arquivo/ANDEF_MANUAL_BOAS PRATICAS_APLICACAO_web.pdf $>$. Acesso em: 10 ago. 2013.
AGÊNCIA NACIONAL DE VIGILÂNCIA SANITÁRIA - ANVISA. Reavaliação de agrotóxico: 10 anos de proteção à população. Brasília: ANVISA, 2010. Disponível em: $<$ http://www.anvisa. gov.br $>$. Acesso em: 27 out. 2012.

BRASIL. Decreto-Lei no 4074, de 4 de janeiro de 2002. Regulamenta a Lei no 7.802, de 11 de julho de 1989, que dispõe sobre a pesquisa, a experimentação, a produção, a embalagem e rotulagem, o transporte, o armazenamento, a comercialização, a propaganda comercial, a utilização, a importação, a exportação, o destino final dos resíduos e embalagens, o registro, a classificação, o controle, a inspeção e a fiscalização de agro tóxicos, seus componentes e afins, e dá outras providências. Diário Oficial [da] União, Brasília, 08, jan. 2002. Seção 1, p. 1. Disponível em: <http://www.sindag.com.br>. Acesso em: 10 mar. 2013.

. Lei $n^{\circ}$. 7.802, de 11 de julho de 1989. Dispõe sobre a pesquisa, a experimentação, a produção, a embalagem e rotulagem, o transporte, o armazenamento, a comercialização, a propaganda comercial, a utilização, a importação, a exportação, o destino final dos resíduos e embalagens, o registro, a classificação, o controle, a inspeção e a fiscalização de agrotóxicos, seus componentes e afins, e dá outras providencias. Diário Oficial [da] União, Brasília, 12, jul. 1989. Seção 1, p. 11459-11460. Disponível em: <http//www.andef.com.br/ legislacao/port84.htm-30k>. Acesso em: 12 mai 2013.

CASADO, V. Falta de informação aumenta perigo de agrotóxicos. Londrina: Folha de Londrina, 2005. p. 4-5. (Folha Rural, n. 2).

CASTELO BRANCO, M. Avaliação do conhecimento do rótulo dos inseticidas por agricultores em uma área agrícola do Distrito Federal. Horticultura Brasileira, Brasília, v. 21, n. 3, p. 570-573, 2003.

CASTRO, J. S. M.; CONFALONIERI, U. Uso de agrotóxicos no Município de Cachoeiras de Macacu (RJ). Ciência \& Saúde Coletiva, Rio de Janeiro, v. 10, n. 2, p. 472-482, 2005.

CATANO, H. C.; CARRANZA, E.; HUAMANÍ, C.; HERNÁNDES, A. F. Plasma cholinesterase levels and health symptoms in peruvian farm workers exposed to organophosphate pesticides. Archives of Environmental Contamination and Toxicology, Paron, AR, USA, v. 55, n. 1, p. 153-159, 2008.

CERQUEIRA, G. S.; ARRUDA, V. R.; FREITAS, A. P. F.; OLIVEIRA, T. L.; VASCONCELOS, T. C.; MARIZ, S. R. Dados da Exposição ocupacional aos agrotóxicos em um grupo assistido por uma Unidade Básica de Saúde na cidade de Cajazeiras, PB. RevInter: Revista Intertox 
de Toxicologia, Risco Ambiental e Sociedade, São Paulo, v. 3, n. 1, p. 16-28, 2010.

DOMINGUES, B. Saúde. Proteção para quem? RADIS Comunicação em Saúde, Rio de Janeiro, v. 1, n. 95, p. 11-15, 2010.

DOMINGUES, M. R.; BERNARDI, M. R; ONO, E. Y. S; ONO A. M. Agrotóxicos: riscos à saúde do trabalhador rural. Semina: Ciências Biológicas e da Saúde, Londrina, v. 25, n. 1, p. 45-54, 2004.

FARAHAT, F. M.; FENSKE, R. A.; OLSON, J. R.; GALVIN, K.; BONNER, M. R.; ROHLMAN, D. S.; FARAHAT, T. M.; LEIN, P. J.; ANGER, W. K. Chlorpyrifos exposures in Egyptian cotton field workers. Neurotoxicology, Philadelphia, v. 31, n. 3, p. 297-304, 2010

FARIA, N. M. X.; FACCHINI, L. A.; FASSA, A. C. G.; TOMASI, E. Trabalho rural e intoxicações por agrotóxicos. Cadernos de Saúde Pública, Rio de Janeiro, v. 20, n. 5, p. 1298-308, 2004.

FARIA, N. M. X.; ROSA, J. A. R.; FACCHINI, L. A. Intoxicações por agrotóxicos entre trabalhadores rurais de fruticultura, Bento Gonçalves, RS. Revista de Saúde Pública, São Paulo, v. 43, n. 2, p. 335-344, 2009.

FERNANDES, V. A.; SILVA, L. F.; MESQUITA, T. R. R.; CAPETTINI, L. S. A.; RODRIGUES, A. L. P.; SANTOS, S. L. Uso de pesticidas na agricultura - Análise da prática na cidade de Ibirité/MG. Scientia Plena, Sergipe, v. 8, n. 3, p. 1-6, 2012.

GARCIA, E. G. Segurança e saúde no trabalho rural com agrotóxicos: contribuição para uma abordagem mais abrangente. 1996. Dissertação (Mestrado em Saúde Pública) - Universidade de São Paulo, São Paulo.

IIDA, I. Ergonomia: projeto e produção. 2. ed. São Paulo: Edgard Blücher, 2005. 632 p.

INSTITUTO BRASILEIRO DE GEOGRAFIA E ESTATÍSTICA - IBGE. Indicadores de desenvolvimento sustentável: Brasil 2012. Estudos e Pesquisas. Rio de Janeiro: IBGE, 2012. 350 p. (Informação Geográfica, n. 9).

$\begin{array}{lrr}\text { INSTITUTO PARANAENSE } & \text { DE } \\ \text { DESENVOLVIMENTO ECONÔMICO E SOCIAL }\end{array}$ - IPARDES. Curitiba: Ipardes, 2013. Disponível em: $\quad<$ http://www.ipardes.gov.br/index.php?pg conteudo $=1 \&$ cod_conteudo $=1>$. Acesso em: 17 out. 2013.

IPARDES. Leituras regionais. Mesorregião Geográfica Norte Central Paranaense/Instituto Paranaense de Desenvolvimento Econômico e Social. Curitiba: IPARDES - BRDE, 2004. 146 p.
JACOBSON, L. S. V.; HACON, S. S.; ALVARENGA, L.; GOLDSTEIN, R. A.; GUMS, C.; BUSS, D. F.; LEDA, L. R. Comunidade pomerana e uso de agrotóxicos: uma realidade pouco conhecida. Ciência \& Saúde coletiva, Rio de Janeiro, v. 14, n. 6, p. 2239-2249, 2009.

LIMA, C. A. B.; GRÜTZMACHER, D. D.; KRÜGER, L. G.; GRÜTZMACHER, A. D. Diagnóstico da exposição ocupacional a agrotóxicos na principal região produtora de pêssego para indústria do Brasil. Ciência Rural, Santa Maria, v. 39, n. 3, p. 900-903, 2009.

MARQUES, C. R. G.; NEVES, P. M. O. J.; VENTURA, M. U. Diagnóstico do conhecimento de informações básicas para o uso de agrotóxicos por agricultores de hortaliças da Região de Londrina. Semina: Ciências Agrárias, Londrina, v. 31, n. 3, p. 547-556, 2010.

MARTINS, M. K. S.; CERQUEIRA, G. S.; SAMPAIO, A. M. A.; LOPES, A. A.; FREITAS, R. M. Exposição ocupacional aos agrotóxicos: um estudo transversal. RevInter Revista Intertox de Toxicologia, Risco Ambiental e Sociedade, São Paulo, v. 5, n. 3, p. 6-27, 2012.

MONQUEIRO, P. A.; INÁCIO, E. M.; SILVA, A. C. Levantamento de agrotóxicos e utilização de equipamento de proteção individual entre os agricultores da região de araras. Arquivos do Instituto Biológico, São Paulo, v. 76, n. 1, p. 135-139, 2009.

MOREIRA, J. C.; JACOB, S. C.; PERES, F.; LIMA, J. S.; MEYER, A.; OLIVEIRA-SILMA, J. J.; SARCINELLI, P. N.; BATISTA, D. F.; EGLER, M.; FARIA, M. V. C.; ARAÚJO, A. J.; KUBOTA, A. H.; SOARES, M. O.; ALVES, S. R.; MOURA, C. M.; CURI, R. Avaliação integrada do impacto do uso de agrotóxicos sobre a saúde humana em uma comunidade agrícola de Nova Friburgo, RJ. Ciência \& Saúde Coletiva, Rio de Janeiro, v. 7, n. 2, p. 299-311, 2002.

NGO, M. A.; O'MALleY, M.; MAIBACH, H. Percutaneous absorption and exposure assessment of pesticides. Journal of Applied Toxicology, Malden, USA, v. 30, n. 2, p. 91-114, 2010.

PERES, F.; MOREIRA, J. C.; DUBOIS, G. S. Agrotóxicos, saúde e ambiente: uma introdução ao tema. In: PERRES, F.; MOREIRA, J. C. (Org.). É veneno ou remédio? Agrotóxicos, saúde e ambiente. Rio de Janeiro: Editora FIOCRUZ, 2003. p. 21-41.

PERES, F.; MOREIRA, J. C.; LUZ, C. Os impactos dos agrotóxicos sobre a saúde e o meio ambiente. Ciência \& Saúde Coletiva, Rio de Janeiro, v. 12, n. 1, p. 4, 2007.

SANDERS, M. S., McCORMICK, E. J. Human factors in engineering and design. 7. ed. Nova Iorque: McGrawHill, 1993. 704 p. 
SILVA, J. M.; NOVATO-SILVA, E.; PINHEIRO, T. M. M. Agrotóxico e trabalho: uma combinação perigosa para a saúde do trabalhador rural. Ciência \& Saúde Coletiva, Rio de Janeiro, v. 10, n. 4, p. 891-903, 2005.

SISTEMA NACIONAL DE INFORMAÇÕES TÓXICO FARMACOLÓGICAS - SINITOX. Manguinhos: Sinitox, 2013. Disponível em: <http://www.fiocruz.br/ sinitox_novo/cgi/cgilua.exe/sys/start.htm?tpl=home $>$. Acesso em: 18 jun. 2013.

THUNDIYIL, J. G.; STOBER, J.; BESBELLI, N.; PRONCZUC, J. Acute pesticide poisoning: a proposed classification tool. Bulletin World Health Organization, v. 86, n. 3, p. 205-209, 2008.
VITALI, M.; PROTANO, C.; DEL MONTE, A.; ENSABELLA, F.; GUIDOTTI, M. Operative modalities and exposure to pesticides during open field treatments among a group of agricultural subcontractors. Archives of Environmental Contamination and Toxicology, New York, v. 57, n. 1, p. 193-202, 2009.

YAMASHITA, M. G. N.; SANTOS, J. E. G. Rótulos e bulas de agrotóxicos: parâmetros de legibilidade tipográfica. In: PASCHOARELLI, L. C.; MENEZES, M. S. (Org.). Design e ergonomia: aspectos tecnológicos. São Paulo: Editora UNESP, Cultura Acadêmica, 2009. p. 197-223. 
